\title{
Prevalence of Posttranscatheter Aortic Valve Implantation Vascular Complications in Real Life
}

\author{
Anthony Matta $\mathbb{D}^{1,2}$ Ronan Canitrot, ${ }^{1}$ Vanessa Nader, ${ }^{1,3}$ Frederic Bouisset, ${ }^{1}$ \\ Thibault Lhermusier, ${ }^{1}$ Francisco Campelo-Parada, ${ }^{1}$ Etienne Grunenwald, ${ }^{4}$ \\ Bertrand Marcheix, ${ }^{4}$ Meyer Elbaz, ${ }^{1}$ Didier Carrie, ${ }^{1}$ and Jerome Roncalli $\mathbb{D}^{1}$ \\ ${ }^{1}$ Department of Cardiology, Institute CARDIOMET, University Hospital of Toulouse, Toulouse, France \\ ${ }^{2}$ Faculty of Medicine, Holy Spirit University of Kaslik, Kaslik, Jounieh, Lebanon \\ ${ }^{3}$ Faculty of Pharmacy, Lebanese University, Beirut, Lebanon \\ ${ }^{4}$ Department of Cardiac Surgery, Institute CARDIOMET, University Hospital of Toulouse, Toulouse, France
}

Correspondence should be addressed to Jerome Roncalli; roncalli.j@chu-toulouse.fr

Received 17 January 2021; Revised 13 September 2021; Accepted 21 September 2021; Published 12 October 2021

Academic Editor: Stefano Rigattieri

Copyright $(92021$ Anthony Matta et al. This is an open access article distributed under the Creative Commons Attribution License, which permits unrestricted use, distribution, and reproduction in any medium, provided the original work is properly cited.

Background. Vascular complications (VCs) are commonly observed after transfemoral transcatheter aortic valve implantation (TAVI) procedures. Closure devices for the access site were developed to reduce their incidence. We aim to evaluate the prevalence, predictors, and outcomes of the occurrence of post-TAVI VCs. Materials and Methods. A retrospective study was conducted on 1336 consecutive patients who underwent TAVI at the University Hospital of Toulouse, France, between January 2016 and March 2020. All included procedures were performed through the common femoral artery, and ProGlide ${ }^{\circledR}$ was the used closure device. The studied population was divided into two groups depending on the occurrence of VCs defined according to Valve Academic Research Consortium-2 criteria. Results. The mean age of the studied population was $84.4 \pm 6.9$, and $48 \%$ were male. $90 \%$ of TAVI interventions were performed through the right femoral artery. The prevalence of VCs was $18.8 \%$, and 3.7\% were major. Prolonged procedure duration was an independent predictor of VCs. Using the right access site and smaller introducer size $(14 \mathrm{Fr}$ ) were preventive factors. No significant difference in mortality rate was detected between the two groups. Conclusion. This study showed a low prevalence for post-TAVI VCs, especially for the major type. An increase in bleeding events and prolonged cardiac care unit stay were the common adverse outcomes.

\section{Introduction}

Degenerative aortic stenosis is the most common valvular heart disease affecting more than $2 \%$ of the population aged above 65 years $[1,2]$. Surgical valve replacement is the traditional recommended therapeutic approach. Recently, transcatheter aortic valve implantation (TAVI) has revolutionized the management of severe aortic stenosis, and its indication was extended to low-surgical-risk patients [3]. TAVI becomes the intervention of choice in high-operativerisk patients and an alternative option for those at low and intermediate risk [4-6].

Over eighteen years of experience, the efficacy and safety of the TAVI procedure have been established. TAVI is gaining ground in the management of aortic stenosis for several factors such as minimally invasive intervention performed under local anesthesia and the new technical advances. Instead, a higher rate of vascular complications is observed after TAVI compared to surgical valve replacement [7]. The common femoral artery is the most often used artery, and different local closure system devices were developed to reduce the occurrence of access site complications. The use of the ProGlide ${ }^{\circledast}$ closure device prevailed during transfemoral TAVI.

Herein, we evaluate the prevalence of vascular complications after transfemoral TAVI using ProGlide ${ }^{\circledast}$ for access site closure and their impact on periprocedural outcomes. 


\section{Materials and Methods}

2.1. Study Design and Population. An observational retrospective study was conducted on 1336 consecutive patients referred for TAVI at the structural and interventional cardiology department at the University Hospital of Toulouse, France, between January 2016 and March 2020. Patients with nontransfemoral TAVI (transaortic, transcarotid, transapical, and subclavian) or with incomplete data were excluded from the study. The included TAVI procedures during the fixed period of time were performed through the right or left common femoral artery by the same senior operators. The crossover technique for vascular access was systematically performed before device implantation. Vascular sheaths (7 Fr) were placed in both femoral arteries, preclosing the selected femoral artery for valve delivery via two ProGlide ${ }^{\circledR}$ prior to upsizing the sheath to 14-20 Fr. After that, intravenous 5000 IU of heparin was given. A standard right ventricular stimulation (temporary pacing) was conducted while implanting the valve. Following successful valve implantation, ProGlide ${ }^{\circledR}$ was the used ipsilateral femoral access closure device in all included patients, and $\mathrm{FemoSeal}^{\circledR}$ was used for the contralateral access site after protamine sulfate administration. It is noteworthy that an angiographic control of the femoral access site is consistently conducted to assess for vascular complications before the closure process. All TAVI procedures were conducted in the presence of an interventional cardiologist, cardiovascular surgeon, and cardiac anesthesiologist. Depending on the occurrence of vascular complications (VCs), the studied population was divided into 2 groups: those with post-TAVI vascular complications versus others (Figure 1). Vascular complications were defined according to Valve Academic Research Consortium-2 criteria [1].

2.2. Data Collection and End Points. Data concerning baseline characteristics (age and sex), cardiovascular risk factors (diabetes mellitus, systemic hypertension, smoking, dyslipidemia, and BMI), medical treatment (aspirin, P2Y12 inhibitors, and oral anticoagulant), previous medical history (prior MI, PCI, CABG, stroke, carotid, and peripheral artery disease), concomitant comorbidities (chronic respiratory disease, renal replacement therapy, and atrial fibrillation), and previous valvuloplasty and TAVI procedure (indication, femoral access site, introducer sheath size, valve sizes, valve types, and procedure duration) were collected. The study has been conducted according to the principles outlined in the Declaration of Helsinki. Post-TAVI adverse clinical outcomes were defined as death from any cause, bleeding (minor, major, or life-threatening), vascular complications (minor or major), stroke, pacemaker implantation, and cardiac care unit admission. We primarily aim to determine the incidence of post-TAVI vascular complications, the associated predictors, and post-TAVI adverse clinical outcomes listed above.

2.3. Statistical Analysis. Categorical variables were summarized as number and percentage and continuous variables as mean \pm standard deviations. Continuous variables were compared with the use of the $t$-test, as appropriate, and categorical variables with the use of $\chi^{2}$ or Fisher's exact test, as appropriate. A stepwise logistic regression analysis including all variables with $p$ value $<0.2$ in the univariate analysis comparing the post-TAVI vascular complications' group to no post-TAVI vascular complications' group was conducted to assess predictors and adverse clinical outcomes significantly associated with the occurrence of post-TAVI vascular complications. A two-sided $p$ value $<0.05$ was considered as statistical significance. All statistical analyses were carried out by using SPSS version 20.

\section{Results}

Out of 1336 consecutive patients who underwent TAVI, 1055 were eligible for inclusion in the study, and 281 were excluded. Baseline and demographic characteristics of the studied population are shown in Table 1 . The mean age was 84.4 , and $48 \%$ of patients were male. The population was at a higher surgical risk with a predicted mortality of $6 \pm 5.5$ by STS-PROM and of $14.2 \pm 9.9$ by EuroSCORE1. Over half of the studied population were classified at NYHA II. The prevalence of population distribution by cardiovascular risk factors was $69.5 \%$ for systemic hypertension, $27.4 \%$ for diabetes mellitus, $42.7 \%$ for dyslipidemia, and $2.1 \%$ for smoking. Concerning previous medical history, the prevalence of myocardial infarction, stroke, peripheral artery disease, carotid artery disease, atrial fibrillation, and chronic respiratory disease was $8.2 \%, 10.4 \%, 7.4 \%, 3.5 \%, 37.8 \%$, and $17.8 \%$, respectively. Prior percutaneous coronary intervention, coronary artery bypass graft, and valvuloplasty were, respectively, observed in $19.8 \%, 6 \%$, and $11.2 \%$ of the whole population. Moreover, $19.1 \%$ of the studied population did not receive any antithrombotic treatment, and $26.4 \%$ received single antiplatelet therapy and $19.7 \%$ dual antiplatelet therapy. Overall, $24.3 \%$ were on an anticoagulant therapy alone and $10.5 \%$ in combination with antiplatelet therapy.

Most TAVI procedures were performed for severe aortic stenosis (93.5\%) using the right femoral access site in $90 \%$ of cases. The introducer sheath size varies from $14 \mathrm{Fr}(59.9 \%)$ to $20 \mathrm{Fr}(0.9 \%)$. The implanted valves were Edwards SAPIEN (51\%), CoreValve Evolut (44.2\%), and ACURATE (4.8\%). Implanted valves' diameters range from less than $25 \mathrm{~mm}$ (26.3\%) to more than $30 \mathrm{~mm}(8.6 \%)$. Most of TAVI procedures' duration was between 60 and $120 \mathrm{~min}$. The characteristics of TAVI procedures are shown in Table 2.

Post-TAVI vascular complications (VCs) were observed in $18.8 \%$ of the entire population, and $3.7 \%$ were major (Table 3). The vascular complications have been treated by simple external compression, balloon inflation for residual stenosis or mild leakage, covered stent implantation (15.6\%), or surgical approach (1.5\%). We note that only three procedures were converted from percutaneous to open-heart surgery for severe vascular complications (aortic rupture). Then, the studied population was divided into 2 groups: post-TAVI VC group $(N=199)$ and post-TAVI with no-VC group $(N=856)$. Except for pacemaker implantation, postTAVI adverse clinical outcomes including death, stroke, bleeding, and cardiac care unit admission were more 


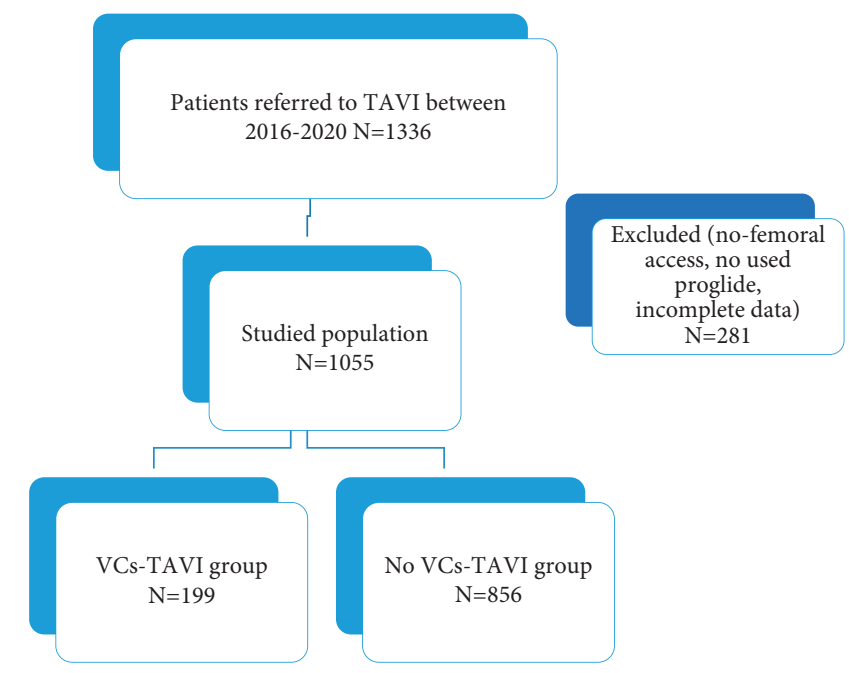

FIgURE 1: Study flowchart.

TABLE 1: Baseline characteristics of the studied population.

\begin{tabular}{|c|c|c|c|c|}
\hline & $\begin{array}{l}\text { Whole population } \\
\qquad(N=1055)\end{array}$ & $\begin{array}{c}\text { Post-TAVI vascular } \\
\text { complication group }(N=199)\end{array}$ & $\begin{array}{l}\text { Post-TAVI without vascular } \\
\text { complication group }(N=856)\end{array}$ & $p$ value \\
\hline Age $($ mean \pm SD $)$ & $84.4 \pm 6.9$ & $84.8 \pm 7.3$ & $84.3 \pm 6.9$ & 0.31 \\
\hline \multicolumn{5}{|l|}{$\operatorname{Sex}(N, \%)$} \\
\hline Male & $506(48)$ & $97(48.7)$ & $409(47.8)$ & 0.8 \\
\hline \multicolumn{5}{|l|}{ CVRF $(N, \%)$} \\
\hline Systemic hypertension & $733(69.5)$ & $150(75.4)$ & $538(68.3)$ & 0.04 \\
\hline Diabetes mellitus & $289(27.4)$ & $58(29.1)$ & $231(27)$ & 0.53 \\
\hline Dyslipidemia & $450(42.7)$ & $91(45.7)$ & $359(41.9)$ & 0.33 \\
\hline Smoker & $22(2.1)$ & $7(3.5)$ & $15(1.8)$ & 0.11 \\
\hline NYHA class $(N, \%)$ & & & & 0.08 \\
\hline I & $16(1.5)$ & $3(1.5)$ & $13(1.5)$ & \\
\hline II & $574(54.4)$ & $124(62.3)$ & $450(52.6)$ & \\
\hline III & $415(39.3)$ & $63(31.7)$ & $352(41.1)$ & \\
\hline IV & $50(4.7)$ & $9(4.5)$ & $41(4.8)$ & \\
\hline \multicolumn{5}{|l|}{ Previous medical history $(N, \%)$} \\
\hline Myocardial infarction & $86(8.2)$ & $15(7.5)$ & $71(8.3)$ & 0.72 \\
\hline PCI & $209(19.8)$ & $38(19.1)$ & $171(20)$ & 0.77 \\
\hline Valvuloplasty & $118(11.2)$ & $29(14.6)$ & $89(10.4)$ & 0.09 \\
\hline CABG & $63(6)$ & $11(5.5)$ & $52(6.1)$ & 0.76 \\
\hline Stroke & $110(10.4)$ & $20(10.1)$ & $90(10.5)$ & 0.84 \\
\hline Peripheral artery disease & $78(7.4)$ & $11(5.5)$ & $67(7.8)$ & 0.26 \\
\hline Carotid artery disease & $37(3.5)$ & $10(5)$ & $27(3.2)$ & 0.19 \\
\hline Atrial fibrillation & $399(37.8)$ & $71(35.7)$ & $328(38.3)$ & 0.48 \\
\hline Chronic respiratory disease & $188(17.8)$ & $30(15.1)$ & $158(18.5)$ & 0.26 \\
\hline \multicolumn{5}{|l|}{ Antithrombotic therapy $(N, \%)$} \\
\hline Single antiplatelet & $279(26.4)$ & $61(30.7)$ & $218(25.5)$ & 0.13 \\
\hline Dual antiplatelet & $208(19.7)$ & $31(15.6)$ & $177(20.7)$ & 0.1 \\
\hline Oral anticoagulant & $256(24.3)$ & $48(24.1)$ & $208(24.3)$ & 0.95 \\
\hline Anticoagulant + antiplatelet & $111(10.5)$ & $18(9)$ & $93(10.9)$ & 0.45 \\
\hline $\begin{array}{l}\text { Renal replacement } \\
\text { therapy }(N, \%)\end{array}$ & $19(1.8)$ & $3(1.5)$ & $16(1.9)$ & 0.73 \\
\hline $\mathrm{BMI}($ mean $\pm \mathrm{SD})$ & $26 \pm 4.8$ & $26.6 \pm 6.2$ & $25.9 \pm 4.7$ & 0.06 \\
\hline EuroSCORE1 (mean $\pm \mathrm{SD})$ & $14.2 \pm 9.9$ & $14.6 \pm 10.9$ & $14.1 \pm 9.7$ & 0.51 \\
\hline STS-PROM $($ mean \pm SD $)$ & $6 \pm 5.5$ & $6.1 \pm 5$ & $5.9 \pm 5.5$ & 0.78 \\
\hline
\end{tabular}

*TAVI: transcatheter aortic valve implantation; CVRF: cardiovascular risk factors; NYHA: New York Heart Association; PCI: percutaneous coronary intervention; CABG: coronary artery bypass graft; BMI: body mass index. 
TABLE 2: Characteristics of transcatheter aortic valve implantation (TAVI) procedures.

\begin{tabular}{|c|c|c|c|c|}
\hline & $\begin{array}{l}\text { Whole population } \\
\qquad(N=1055)\end{array}$ & $\begin{array}{c}\text { Post-TAVI vascular } \\
\text { complication group }(N=199)\end{array}$ & $\begin{array}{l}\text { Post-TAVI without vascular } \\
\text { complication group }(N=856)\end{array}$ & $p$ value \\
\hline TAVI indication $(N, \%)$ & & & & $<0.001$ \\
\hline Severe aortic stenosis & $986(93.5)$ & $180(90.5)$ & $806(94.2)$ & \\
\hline $\begin{array}{l}\text { Others (aortic regurgitation/ } \\
\text { prosthetic valve degeneration) }\end{array}$ & $69(6.6)$ & $19(9.5)$ & $50(5.8)$ & \\
\hline Right access site $(N, \%)$ & $949(90)$ & $171(85.9)$ & $778(90.9)$ & 0.03 \\
\hline \multicolumn{5}{|l|}{ Introducer sheath size $(N, \%)$} \\
\hline $14 \mathrm{Fr}$ & $632(59.9)$ & $101(50.8)$ & $531(62)$ & 0.04 \\
\hline $16 \mathrm{Fr}$ & $329(31.2)$ & $75(37.7)$ & $254(29.7)$ & \\
\hline $18 \mathrm{Fr}$ & $84(8)$ & $20(10.1)$ & $64(7.5)$ & \\
\hline $20 \mathrm{Fr}$ & $10(0.9)$ & $3(1.5)$ & $7(0.8)$ & \\
\hline Valve types $(N, \%)$ & & & & 0.17 \\
\hline Edwards SAPIEN & $538(51)$ & $96(48.2)$ & $442(51.6)$ & \\
\hline CoreValve Evolut & $466(44.2)$ & $98(49.2)$ & $368(43)$ & \\
\hline ACURATE & $51(4.8)$ & $5(2.5)$ & $46(5.4)$ & \\
\hline Valve size $(N, \%)$ & & & & 0.7 \\
\hline$\leq 25$ & $277(26.3)$ & $50(25.1)$ & $227(26.5)$ & \\
\hline ]25-30] & $687(65.1)$ & $129(64.8)$ & $558(65.2)$ & \\
\hline$>30$ & $91(8.6)$ & $20(10.1)$ & $71(8.3)$ & \\
\hline Procedure duration $(N, \%)$ & & & & $<0.001$ \\
\hline$\leq 60 \mathrm{~min}$ & $154(14.6)$ & $22(11.1)$ & $132(15.4)$ & \\
\hline ]60-120] $\mathrm{min}$ & 864 (81.9) & $159(79.9)$ & $705(82.4)$ & \\
\hline$>120 \mathrm{~min}$ & $37(3.5)$ & $18(9)$ & $19(2.2)$ & \\
\hline
\end{tabular}

TABLE 3: Description of the observed vascular complications.

\begin{tabular}{lc}
\hline Type of vascular complications & $N=199(\%)$ \\
\hline Aortic dissection & 0.5 \\
Aortic rupture & 1.5 \\
Unplanned endovascular stenting & 15.6 \\
Unplanned surgery & 1.5 \\
Ipsilateral lower extremity ischemia & 0.5 \\
Access site hematoma & 69.8 \\
Pseudoaneurysm & 6 \\
Arteriovenous fistula & 1.5 \\
Dissection & 2 \\
Residual nonsignificant stenosis & 1 \\
\hline
\end{tabular}

common in the post-TAVI vascular complications' group (Figure 2). Univariate analyses have shown significant differences at the 0.2 level between the two groups in terms of distribution of systemic hypertension, smoking, NYHA class, previous valvuloplasty, carotid artery disease, BMI, antithrombotic regimen, right access site, introducer sheath size, valve types, procedure duration, death, bleeding, and cardiac care unit stay (Tables 1 and 2 and Figure 2). After adjusting for confounding variables listed above, the multivariate logistic regression showed that longer procedure duration (more than $120 \mathrm{~min}$ ) is an independent predictor for $\mathrm{VCs}(\mathrm{OR}=1.8 ; 95 \% \mathrm{CI}=[1.2 ; 2.8])$ (Table 4). Also, negative associations between $\mathrm{VCs}$ and right access site $(\mathrm{OR}=0.6 ; 95 \% \mathrm{CI}=[0.37 ; 0.99])$ and smaller introducer sheath size $14 \mathrm{Fr} \quad(\mathrm{OR}=0.63 ; 95 \% \quad \mathrm{CI}=[0.45 ; 0.89])$ have been shown. Post-TAVI vascular complications' group was more predisposed to bleeding ( $\mathrm{OR}=2.57 ; 95 \%$ $\mathrm{CI}=[1.8 ; 3.6])$ and prolonged cardiac care unit stay $(\mathrm{OR}=2$; $95 \% \mathrm{CI}=[1.4 ; 3])$.

\section{Discussion}

This study showed an overall prevalence of post-TAVI VCs at $18.8 \%$ while using the ProGlide ${ }^{\circledast}$ device for the closure of the femoral access site. Compared to the old manual compression method, closure device systems are less painful and provide faster hemostasis, earlier mobilization, and discharge [8]. Indeed, Perclose ProGlide ${ }^{\circledast}$ device is used increasingly worldwide during TAVI procedures and endovascular aneurysm repair interventions [8]. A current published study showed an incidence of post-TAVI vascular complications at $21 \%$ [9], and similar rates were found in previously published studies [10-13]. The prevalence of major vascular complications was $3.7 \%$, while most reported values in the literature range between $1.9 \%$ and $30.7 \%$ $[9,14-18]$. The lowest prevalence revealed by our study may be related to the largest sample size, new valve generations, older age of the studied population requiring delicate and careful manipulations, operators' experience, and homogeneity of the closure device system (exclusively Perclose ProGlide ${ }^{\circledast}$ ). A similar rate at $3.4 \%$ of post-TAVI VCs was reported in a study comparing the use of Perclose ProGlide between patients undergoing TAVI and endovascular aneurysm repair [8]. The higher prevalence of minor VCs compared to the major VCs is due to the VARC-2 definition classifying all postprocedural access site hematomas into minor VCs.

Smaller sheaths ( $14 \mathrm{Fr}$ ) were significantly associated with a lower rate of VCs in accordance to what was previously reported $[9,19]$. Prior studies identified sheaths above $19 \mathrm{Fr}$ as an independent predictor for VCs [16, 20, 21]. Usually, the choice of sheaths is influenced by the valve type and size. In fact, two-thirds of used valves through smaller sheaths 


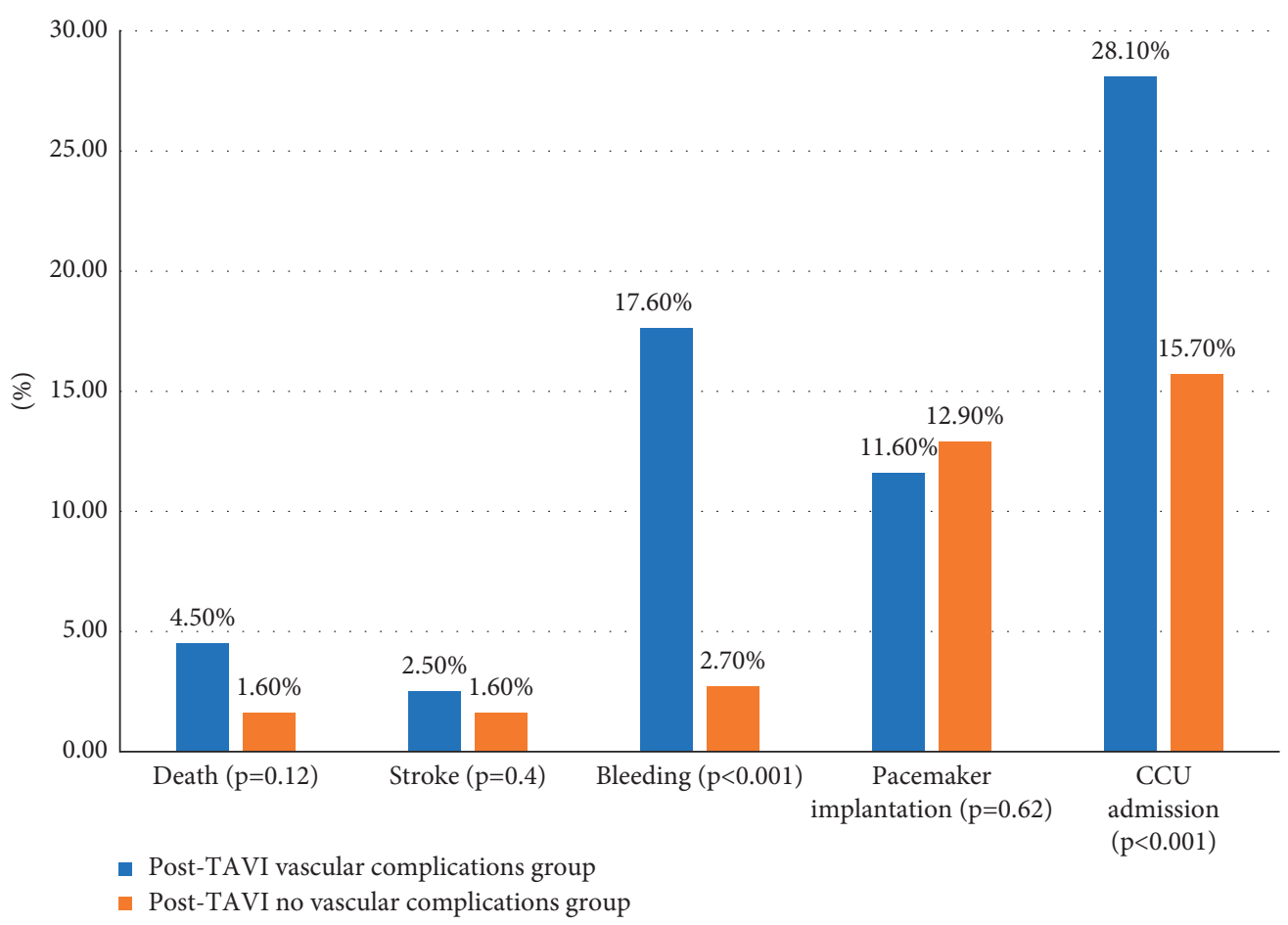

FIGURE 2: Univariate analysis comparing the prevalence of post-TAVI complications between the two groups.

TABLE 4: Stepwise logistic regression studying the association between vascular complications, predictors, and adverse outcomes.

\begin{tabular}{lccc}
\hline Variables & OR & $95 \%$ CI & $p$ value \\
\hline Smoking & 1.67 & {$[0.58 ; 4.77]$} & 0.33 \\
Hypertension & 1.42 & {$[0.97 ; 2.08]$} & 0.06 \\
NYHA class & 0.78 & {$[0.6 ; 1.02]$} & 0.07 \\
TAVI indication & 0.54 & {$[0.29 ; 0.99]$} & 0.04 \\
Prior valvuloplasty & 1.29 & {$[0.79 ; 2.1]$} & 0.3 \\
Carotid disease & 1.57 & {$[0.71 ; 3.45]$} & 0.26 \\
BMI & 1.02 & {$[0.98 ; 1.05]$} & 0.3 \\
SAPT & 1.17 & {$[0.8 ; 1.7]$} & 0.4 \\
DAPT & 0.73 & {$[0.46 ; 1.16]$} & 0.18 \\
Right access site & 0.6 & {$[0.37 ; 0.99]$} & 0.04 \\
Introducer sheath size 14Fr & 0.63 & {$[0.45 ; 0.89]$} & 0.009 \\
Valve types & 0.82 & {$[1.2 ; 2.8]$} & 0.22 \\
Procedure duration & 1.8 & {$[0.65 ; 4.09]$} & 0.005 \\
Death & 1.63 & {$[1.8 ; 3.6]$} & 0.29 \\
Bleeding & 2.57 & {$[1.4 ; 3]$} & $<0.001$ \\
CCU stay (>24 hours) & 2 & $<0.001$ \\
\hline
\end{tabular}

*NYHA: New York Heart Association; BMI: body mass index; SAPT: single antiplatelet therapy; DAPT: dual antiplatelet therapy; TAVI: transcatheter aortic valve implantation; CCU: cardiac care unit.

(14 Fr) were balloon-expandable (63.4\%), while self-expandable valves $(67.5 \%)$ were often used in larger sheaths. Taking access through the right common femoral artery is a preventive factor compared to the left side on the occurrence of VCs. This point comparing both access sites is described for the first time in the literature [8-18, 22]. Technical parameters such as the operator to patient position and routine behavior may explain this significant difference in favor for the right access site. Also, it is worthy to mention that the right access site is used by default in real life. Prolonged procedure duration $(>120 \mathrm{~min})$ is an independent predictor for the occurrence of VCs, and systemic hypertension showed a strong trend toward increased risk. We believe that our study is the largest one to report on the prevalence and clinical relevance of vascular complications after transfemoral TAVI procedures.

Lastly, worse clinical outcomes were attributed to the occurrence of VCs after TAVI [19]. An increased length of hospital stay and reduced quality of life were reported $[14,16,18,20]$. The impact of VCs on early mortality is controversial: numerous studies reported an increase in mortality rate $[18,20,23]$, whereas no statistical difference 
was observed in others [24]. Herein, we revealed a significant association with bleeding events and prolonged stay in the cardiac care unit ( $>24$ hours) with no effect on overall mortality rate.

4.1. Limitations. The limitations of the study were the retrospective monocentric nature. Despite the largest sample size, the low prevalence of post-TAVI vascular complications may limit the ability to detect all independent factors. The lack of performing a systemic echo Doppler for the access site after transfemoral TAVI may result in a subjective and misestimation of minor vascular complications. Lastly, CT-scan data were not collected knowing that, except for artery calcification, no predictor factor was previously identified in the literature.

\section{Conclusion}

Vascular complications after transfemoral TAVI procedures constitute the main safety limitations. New valve generations, experienced operators, and closure system devices lead to a dramatic decrease in their incidence. We believe that our study provides an up-to-date on the prevalence, predictors, and impact of post-TAVI VCs in real life. To conclude, using an appropriate sheath size in accordance with the valve type, shortening procedure time, and giving preference for the right access site are daily important parameters. Increased rate of bleeding events and prolonged cardiac care unit stay are the major observed adverse outcomes.

\section{Data Availability}

The data used to support the findings of this study are available from the corresponding author upon request.

\section{Conflicts of Interest}

FB reported grants from Boston SC and personal fees from MSD, Abbott, B. Braun, and Amgen outside the submitted work. BM reported personal fees from Edwards and Medtronic outside the submitted work. JR reported grants from Abbott during the conduct of the study. AM, RC, VN, TL, FCP, EG, ME, and DC declare no conflicts of interest.

\section{Authors' Contributions}

Anthony Matta and Ronan Canitrot contributed equally to this work.

\section{Acknowledgments}

Abbott provided the financial support without any interference in study design, data collection, data analysis, and manuscript writing.

\section{References}

[1] M. J. Czarny and J. R. Resar, "Diagnosis and management of valvular aortic stenosis," Clinical Medicine Insights: Cardiology, vol. 8, pp. 15-24, 2014.
[2] W. J. Manning, "Asymptomatic aortic stenosis in the elderly," Journal of the American Medical Association, vol. 310, no. 14, pp. 1490-1497, 2013.

[3] M. J. Mack, M. B. Leon, V. H. Thourani et al., “Transcatheter aortic-valve replacement with a balloon-expandable valve in low-risk patients," New England Journal of Medicine, vol. 380, no. 18, pp. 1695-1705, 2019.

[4] R. A. Nishimura, C. M. Otto, R. O. Bonow et al., "2014 AHA/ ACC guideline for the management of patients with valvular heart disease: a report of the American college of cardiology/ American heart association task force on practice guidelines," Circulation, vol. 129, pp. e521-643, 2014.

[5] A. Vahanian, O. Alfieri, F. Andreotti et al., "Guidelines on the management of valvular heart disease (version 2012). The joint task force on the management of valvular heart disease of the European society of cardiology (ESC) and the European association for cardio-thoracic surgery (EACTS)," European Heart Journal, vol. 33, pp. 2451-2496, 2012.

[6] R. A. Nishimura, C. M. Otto, R. O. Bonow et al., "2017 AHA/ ACC focused update of the 2014 AHA/ACC guideline for the management of patients with valvular heart disease: a report of the American college of cardiology/American heart association task force on clinical practice guidelines," Circulation, vol. 135, pp. e1159-e1195, 2017.

[7] A. Elmaraezy, A. Ismail, A. I. Abushouk et al., "Efficacy and safety of transcatheter aortic valve replacement in aortic stenosis patients at low to moderate surgical risk: a comprehensive meta-analysis," BMC Cardiovascular Disorders, vol. 17, no. 1, p. 234, 2017.

[8] G. Durmus, E. Belen, A. Bayyigit, and M. M. Can, "Comparison of complication and success rates of proglide closure device in patients undergoing TAVI and endovascular aneurysm repair," BioMed Research International, vol. 2018, Article ID 2687862, 2018.

[9] W. Batchelor, K. Patel, J. Hurt et al., "Incidence, prognosis and predictors of major vascular complications and percutaneous closure device failure following contemporary percutaneous transfemoral transcatheter aortic valve replacement," Cardiovascular Revascularization Medicine, vol. 21, no. 9, pp. 1065-1073, 2020.

[10] V. Babaliaros, C. Devireddy, S. Lerakis et al., "Comparison of transfemoral transcatheter aortic valve replacement performed in the catheterization laboratory (minimalist approach) versus hybrid operating room (standard approach)," JACC: Cardiovascular Interventions, vol. 7, no. 8, pp. 898-904, 2014.

[11] M. Nakamura, T. Chakravarty, H. Jilaihawi et al., "Complete percutaneous approach for arterial access in transfemoral transcatheter aortic valve replacement: a comparison with surgical cut-down and closure," Catheterization and Cardiovascular Interventions, vol. 84, no. 2, pp. 293-300, 2014.

[12] F. L. M. Bernardi, W. F. Gomes, F. S. de Brito et al., "Surgical cutdown versus percutaneous access in transfemoral transcatheter aortic valve implantation: insights from the Brazilian TAVI registry," Catheterization and Cardiovascular Interventions, vol. 86, no. 3, pp. 501-505, 2015.

[13] E. M. Holper, R. J. Kim, M. Mack et al., "Randomized trial of surgical cutdown versus percutaneous access in transfemoral TAVR," Catheterization and Cardiovascular Interventions, vol. 83, no. 3, pp. 457-464, 2014.

[14] K. Hayashida, T. Lefèvre, B. Chevalier et al., "Transfemoral aortic valve implantation," JACC: Cardiovascular Interventions, vol. 4, no. 8, pp. 851-858, 2011. 
[15] L. F. Satler and D. Dvir, "Vascular complications during transcatheter aortic valve replacement," Catheterization and Cardiovascular Interventions, vol. 81, no. 4, pp. 584-585, 2013.

[16] P. Généreux, J. G. Webb, L. G. Svensson et al., "Vascular complications after transcatheter aortic valve replacement: insights from the partner (placement of AoRTic TraNscathetER valve) trial," Journal of the American College of Cardiology, vol. 60, pp. 1043-1052, 2012.

[17] M. A. Chaudhry and M. R. Sardar, "Vascular complications of transcatheter aortic valve replacement: a concise literature review," World Journal of Cardiology, vol. 9, no. 7, pp. 574-582, 2017.

[18] M. Seiffert, R. Schnabel, L. Conradi et al., "Predictors and outcomes after transcatheter aortic valve implantation using different approaches according to the valve academic research consortium definitions," Catheterization and Cardiovascular Interventions: Official Journal of the Society for Cardiac Angiography \& Interventions, vol. 82, pp. 640-652, 2013.

[19] C. Reidy, A. Sophocles, H. Ramakrishna, K. Ghadimi, P. A. Patel, and J. G. T. Augoustides, "Challenges after the first decade of transcatheter aortic valve replacement: focus on vascular complications, stroke, and paravalvular leak," Journal of Cardiothoracic and Vascular Anesthesia, vol. 27, no. 1, pp. 184-189, 2013.

[20] N. M. Van Mieghem, D. Tchetche, A. Chieffo et al., "Incidence, predictors, and implications of access site complications with transfemoral transcatheter aortic valve implantation," The American Journal of Cardiology, vol. 110, no. 9, pp. 1361-1367, 2012.

[21] C. Sari, H. Ayhan, A. Aslan et al., "Predictors and incidence of access site complications in transcatheter aortic valve implantation with the use of new delivery systems," Perfusion, vol. 30, no. 8, pp. 666-674, 2015.

[22] M. R. Sardar, A. M. Goldsweig, J. D. Abbott et al., "Vascular complications associated with transcatheter aortic valve replacement," Vascular Medicine, vol. 22, no. 3, pp. 234-244, 2017.

[23] C. Moretti, M. D'amico, F. D'ascenzo et al., "Impact on prognosis of periprocedural bleeding after TAVI: mid-term follow-up of a multicenter prospective study," Journal of Interventional Cardiology, vol. 27, no. 3, pp. 293-299, 2014.

[24] K. Czerwinska-Jelonkiewicz, I. Michalowska, A. Witkowski et al., "Vascular complications after transcatheter aortic valve implantation (TAVI): risk and long-term results," Journal of Thrombosis and Thrombolysis, vol. 37, pp. 490-498, 2014. 